\title{
The influence of early experiences and university environment for female students choosing geoscience programs: a case study at Universidad de Chile
}

\author{
Tania Villaseñor ${ }^{1,2}$, Sergio Celis ${ }^{3,4}$, Juan Pablo Queupil ${ }^{5}$, Luisa Pinto ${ }^{2,3}$, and Maisa Rojas ${ }^{6,7}$ \\ ${ }^{1}$ Instituto de Ciencias de la Ingeniería, Universidad de O’Higgins, Rancagua, Chile \\ ${ }^{2}$ Departamento de Geología, Universidad de Chile, Santiago, Chile \\ ${ }^{3}$ Escuela de Ingeniería y Ciencias, Universidad de Chile, Santiago, Chile \\ ${ }^{4}$ Núcleo Milenio EDSUP, Santiago, Chile \\ ${ }^{5}$ Centro de Estudios en Educación y Aprendizaje Basado en la Comunidad, \\ Universidad Católica Silva Henríquez, Santiago, Chile \\ ${ }^{6}$ Departamento de Geofísica, Universidad de Chile, Santiago, Chile \\ ${ }^{7}$ Centro de Ciencia del Clima y la Resiliencia, Santiago, Chile
}

Correspondence: Tania Villaseñor (tania.villasenor@uoh.cl)

Received: 31 January 2020 - Revised: 9 May 2020 - Accepted: 11 August 2020 - Published: 6 October 2020

\begin{abstract}
This case study addresses the experiences of female undergraduate students in the geology and geophysics programs at Universidad de Chile. These majors are part of the Faculty of Physical Sciences and Mathematics (FCFM) and have a relatively large proportion of female representation compared to the other engineering and science majors at FCFM that are dominated by male students. We interviewed 12 female students in geoscience majors to understand (a) the reasons for choosing geoscience as a major and (b) their experiences both at FCFM and in geoscience in an institution with a strong masculine environment that aims to increase women's undergraduate enrollment. We found that the decision to pursue a geoscience career was made during high school, and they maintained this decision during the first years of college, which is heavily focused on mathematics and physics, with no geoscience-related courses. During this early period in college, known as the common core program, students perceived a hostile environment due to high academic demands and gender-based discrimination. Their experiences had a positive shift once they started the geoscience courses in their fifth or sixth semester. The relatively large proportion of female students in the geoscience majors at FCFM creates a positive environment in which the participants developed a sense of belonging in the geoscience community. Students also felt that the feminist movement during 2018 in Chile positively influenced their perspectives on
\end{abstract}

their path at FCFM. These findings give insights for developing strategies to increase early interest, participation, and satisfaction of women in science, technology, engineering, and mathematics (STEM) disciplines at various educational levels.

\section{Introduction}

Throughout the world, women have historically been underrepresented in science, technology, engineering, and mathematics (STEM) undergraduate programs. This is attributed to social, cultural, and economic forces in colleges and the workplace (Beede et al., 2011; Seymour, 2002; UNESCO, 2017). The underrepresentation of women in STEM undergraduate degrees has been related, among other factors, to family influence, stereotypes, secondary education structures, and early education classroom experiences (Blackburn, 2017; Dasgupta and Stout, 2014). Retention and graduation of women from STEM majors are further affected by barriers experienced in college (Rosen, 2017) that contribute to a progressive decrease in the presence of women in STEM careers. Geoscience programs are no exception. For example, a recent report showed that female enrollment in US geoscience undergraduate and master programs has declined since 2004, leveling out at around $40 \%$ female representation (American 
Geosciences Institute, 2016). According to another study, the number of science and engineering (including geology and engineering geology) female undergraduate students in Europe leveled off at around 30\% for the period 2002-2010 (European Commission, 2013). Moreover, this underrepresentation at the college level later increases due to an adverse workplace climate in the geosciences (e.g., Geological Society of America, 2018), which in turn negatively influences perceptions within this field for prospective students (e.g., Dasgupta and Asgari, 2004).

During recent decades, developing countries have made some efforts toward higher education access and equity (Clancy and Goastellec, 2007; Naidoo, 2007; Villalobos et al., 2017; World Bank, 2000) with a focus on STEM fields (Marginson et al., 2013). Specifically, there has been a promotion of diversity and its impact on educational outcomes (Codling and Meek, 2006; Dumas-Hines et al., 2001; Gurin et al., 2002) based either on legal considerations (e.g., affirmative action) or the promotion of the inclusion of groups that have been persistently marginalized in the higher education system (Boliver, 2011; Pfeffer, 2008; Shavit, 2007).

In Latin America, access to higher education is increasing, but it is still low compared with the average of Organisation for Economic Co-operation and Development (OECD) member countries (Mendes Braga, 2008; UNESCO, 2014), with women underrepresented in STEM programs (OECD, 2017). In the case of Chile, augmenting the number of people trained in STEM areas is important as it moves from an economy based on the exploitation of natural resources to one in which innovation and technology add additional value to the country's resources (OECD/CAF/ECLAC, 2015). For women, this could enhance their incorporation into the workforce and reduce the salary gap (ComunidadMujer, 2017). In Chile, only $27 \%$ of STEM undergraduate students are females (ComunidadMujer, 2016), while women represent about $19 \%$ of researchers in the engineering and technology workforce (UNESCO, 2019). To increase the participation of women in STEM disciplines, leading universities in Chile have been implementing policies and initiatives to attract and engage female students in STEM programs. One effort is the Equity and Gender Program (PEG, acronym in Spanish) at the Faculty of Physical Sciences and Mathematics at Universidad de Chile (FCFM, acronym in Spanish), implemented in 2014, that offers additional admissions to engineering and science programs in this institution, which has been historically dominated by male students and professors.

The accumulated experience of higher education institutions in the training and education of students, along with social demands for gender parity, has created the need to learn more about the motivations and experiences of female students, with the goal of attracting the best talent (Castillo et al., 2014). Very few studies in Chile have analyzed the experience of female students in academic programs in maledominated disciplines. For example, Salinas and Romaní (2017) and Salinas et al. (2019) investigated the experience of female students in the mining sector, which is the area that employs the largest proportion of geoscience professionals in Chile. These studies show that female students perceive several tensions during their college education due to the male hegemony of the environment, mostly related to gender stereotypes (e.g., not capable of doing the work, low selfefficacy) and uncertainties about their professional development (machista culture in the industry, work-life balance) (Salinas and Romaní, 2017), which is not necessarily perceived as a relevant matter to address by educational institutions (Salinas et al., 2019). However, female students persist in their education despite the challenges and difficulties that the male-dominated mining sector presents because of good salary prospects and improvement of their self-concept and confidence during their education (Salinas and Romaní, 2017).

In the particular case of FCFM, it has been documented that female students perceive a hostile environment related to the expected gender role attributed to women (housewives) that male students consider part of the masculine culture of engineering, as well as sexual objectification of female bodies in public spaces (Bonilla, 2016). This results in an environment that underestimates the academic capacities of female students and that, in turn, in many cases promotes the progressive development of a strong personality among women in order to be heard and validated as future engineers (Bonilla, 2016). In this sense, female students recognize an adverse university environment, and they adapt to manage the difficulties it presents.

This study investigates the choice of major and the experience of female students in geoscience programs at FCFM in an environment that is changing by moving away from a male-dominated legacy, to which the PEG program is contributing. This investigation was carried out during a period of a nationwide feminist movement in response to a culture that normalizes gender-based discrimination, sexual harassment, and the abuse of power (Schuster et al., 2019). This included protests and a strike at FCFM in demand for improved protocols against harassment and abuse, as well as a change in the culture of the college. This context motivated our interest to learn about the experiences of female geoscience students in this male-dominated school. Our purpose then is to evaluate the motivations to pursue a career in geosciences and the perceived challenges and difficulties that women face throughout their education in a masculinized school. In order to accomplish this, we carried out a series of interviews with female students of geology and geophysics at FCFM. We thereby hope to gain insights into strategies that the educational community can implement to close the gender gap in STEM careers and geoscience in particular. 


\section{Background}

\subsection{Inclusion of women in STEM majors in Chile}

Access to higher education in Chile has increased over the past 15 years (Consejo Nacional de Educación, 2019). Women have dominated enrollment in undergraduate programs during this period, reaching $53 \%$ of the total enrollment in 2018 (SIES, 2019). However, they are underrepresented in STEM disciplines, representing around $25 \%$ of the total enrollment during the same period (Sepúlveda and Manquepillán, 2017; Bordón et al., 2018). Not surprisingly, the underrepresentation of women in STEM continues in academic careers. The National Commission for Scientific and Technological Research (CONICYT, acronym in Spanish), the main Chilean public funding agency for scholarships and research, found that in 2016 only $38 \%$ of doctoral scholarships to study abroad were awarded to women (136 out of 360 awardees) and only $27 \%$ of publicly funded research projects were led by women ( 222 out of 802 projects; CONICYT, 2017). The lack of female representation in STEM disciplines may be related to cultural biases and stereotypes regarding the role of women in society, including gender discrimination during their educational experience starting in elementary education (UNESCO, 2017). In addition, the selection of a university program may be affected by the tendency of women to reproduce the college career of their mothers, who have historically chosen careers in health, social sciences, or education (Bordón et al., 2018). The university selection process in Chile seems to present an additional barrier for women to enroll in STEM majors. Highly competitive test scores to obtain a slot in STEM programs, especially the mathematics test that has a strong influence on student admission, tend to discourage women to apply to these majors (Bordón et al., 2018; Díaz et al., 2019). For this reason, it is important that universities adopt affirmative action programs that complement current educational policy reforms (Queupil and Durán, 2018) to enhance enrollment of women in STEM programs (Díaz et al., 2019).

Several programs to attract female applicants to engineering and science majors have recently been implemented in various universities in Chile (Emol, 2020), including the PEG program at FCFM (Espinoza, 2019), reflecting the increasing need for special programs to counterbalance cultural and institutional barriers for women to pursue a career in STEM. The implementation of these programs promoted an increase in the enrollment of female students of about $20 \%-35 \%$ by 2019 (Emol, 2020).

\subsection{Geosciences at Universidad Chile}

In Chile, there are 29 undergraduate programs associated with geosciences offered by 17 universities. As a whole, they offer around 2030 enrollment slots for new students every year. In the particular case of geology programs, enrollment has increased rapidly since 2009 due to the high demand for qualified professionals, mostly in the mining sector (Tapia et al., 2018). At Universidad de Chile, geology and geophysics programs are offered by FCFM. This faculty has over 5800 undergraduate students and offers around 800 regular admission slots every year.

\subsubsection{Admission to FCFM}

The admission process to FCFM is aimed at students interested in studying any of the 13 majors offered by this school: 10 engineering and 3 science programs (Table 1). This means that students interested in geoscience compete for admission slots with students interested in engineering or other science programs, an academic model that is not very common in Chile.

The regular admission process to FCFM is based on the scores obtained on the university admission test, a standardized test that includes four sections: language, mathematics, history, and science. The score that each student presents to apply to FCFM is calculated by weighing the scores obtained on the university admission test and the high school grades. The maximum score for each section is 850 . A weighing score above 730 or 750 points is typical to be admitted to FCFM, which represents a percentile rank of 99th or 100th, respectively. This implies that the admission scores of geology students at FCFM are the highest among other geology programs offered in Chile (Tapia et al., 2018). This is the same for geophysics, a major that is offered at only two universities in Chile.

Even though women score almost as high as men, the number of female students admitted to FCFM has been historically low (Fig. 1). In this context, the PEG program at FCFM was created with the aim of increasing the number of female undergraduate students. It was implemented in 2014 and currently reserves 55 additional spots for female applicants that scored just below the admission cutoff score (PEG, 2020). As shown in Fig. 1, the lowest representation of freshman female students for the period 2007-2018 was $17.2 \%$ in 2010. Since that year, there has been a gradual increase in the number of female students at FCFM, especially since the implementation of the PEG program, leading to the historic enrollment of $32.8 \%$ female admissions in 2018. In addition, the gap in enrollment scores between women and men has decreased in the past few years, with a difference of only 2.29 points in the 2018 cohort (Fig. 1). Other special admission programs at FCFM are common to all colleges at Universidad de Chile. This includes the athletic program (15 slots for FCFM), the education equity program for socioeconomically disadvantaged students (25 slots), the academic excellence program for low-income students (40 slots), and the Program for Indigenous Students (10 slots).

Once female students arrive at FCFM, the issue of internal choice of major arises. As shown in Table 1, there are majors that attract a relatively large proportion of fe- 
Table 1. Number of female students and faculty by major at FCFM in 2017.

\begin{tabular}{lrrrrrr}
\hline Major & $\begin{array}{r}\text { Total } \\
\text { students } \\
(N)\end{array}$ & $\begin{array}{r}\text { Female } \\
\text { students } \\
(N)\end{array}$ & $\begin{array}{r}\text { Female } \\
\text { students } \\
(\%)\end{array}$ & $\begin{array}{r}\text { Total } \\
\text { faculty } \\
(N)\end{array}$ & $\begin{array}{r}\text { Female } \\
\text { faculty } \\
(N)\end{array}$ & $\begin{array}{r}\text { Female } \\
\text { faculty } \\
(\%)\end{array}$ \\
\hline Industrial engineering & 170 & 59 & 35 & 27 & 2 & 7 \\
Civil engineering & 152 & 41 & 27 & 22 & 2 & 9 \\
Geology & 41 & 14 & 34 & 20 & 5 & 25 \\
Mechanical engineering & 138 & 35 & 25 & 16 & 3 & 19 \\
Mining engineering & 54 & 11 & 20 & 15 & 3 & 20 \\
Electrical engineering & 98 & 11 & 11 & 25 & 5 & 20 \\
Computing engineering & 83 & 19 & 23 & 22 & 5 & 23 \\
Chemical and biotechnology engineering & 28 & 10 & 36 & 13 & 5 & 38 \\
Mathematic engineering & 47 & 7 & 15 & 24 & 2 & 8 \\
Astronomy* & 21 & 8 & 38 & 22 & 4 & 18 \\
Physics* & 19 & 3 & 16 & 20 & 2 & 10 \\
Geophysics* & 7 & 4 & 57 & 16 & 3 & 19 \\
\hline Total & 858 & 222 & 26 & 242 & 41 & 17 \\
\hline
\end{tabular}

* Only Bachelor degree after 4 years of study. All engineering and geology majors include Bachelor and professional degrees after 6 years of study. Note that chemical and biotechnology engineering are shown together since both majors share several courses during the first semesters of the programs.
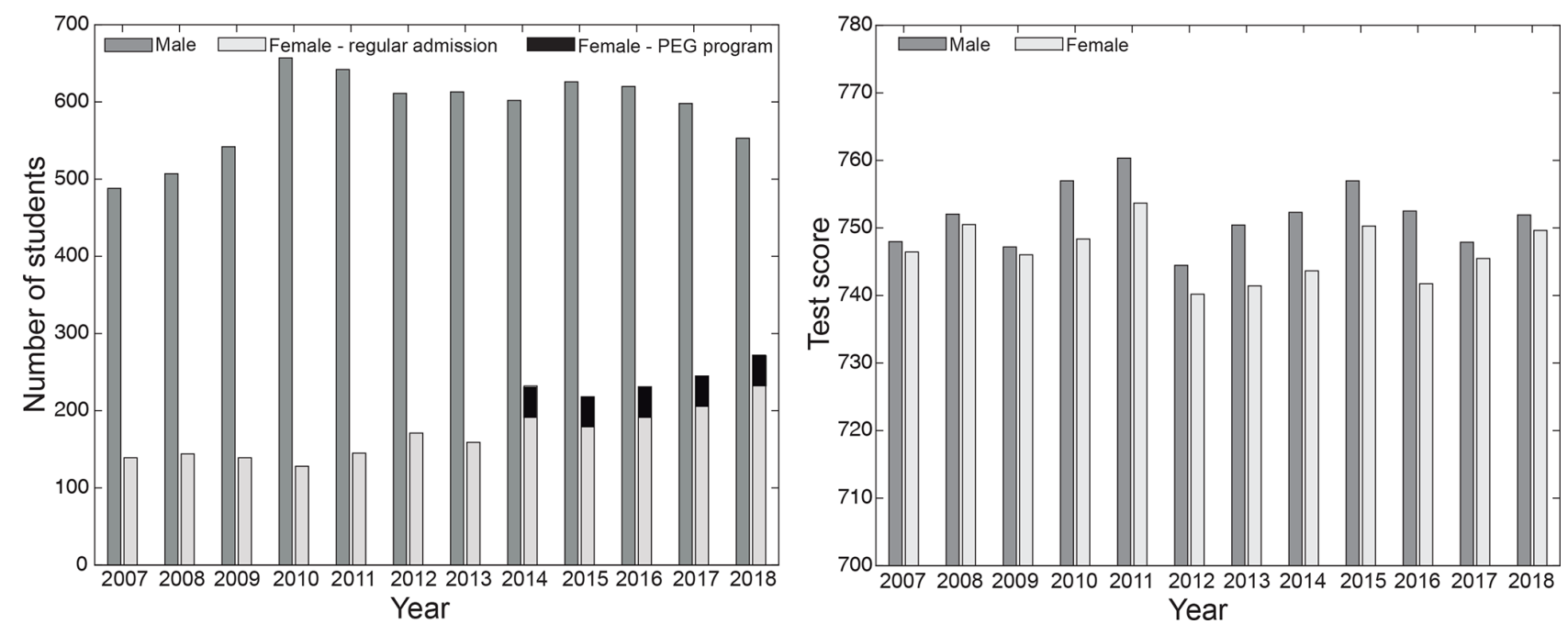

Figure 1. Number of students admitted to FCFM at Universidad de Chile and average enrollment score by gender for the period 2007-2018.

male students, such as geophysics (57\%), astronomy (38\%), chemical and biotechnology engineering (36\%), industrial engineering (35\%), and geology (34\%). On the other hand, there are majors that struggle to attract female students, such as mining engineering (20\%), electrical engineering (11\%), mathematical engineering (15\%), and physics $(16 \%)$. Thus, FCFM represents an appropriate setting to study the female student experience and choice of major among diverse STEM disciplines.

\subsubsection{Academic curriculum at FCFM}

At FCFM all undergraduate students start their academic program with a 2-year common core program, in which all stu- dents, regardless of their major of interest, take the same mandatory courses, which are mostly on mathematics and physics. These courses are not organized by the intended major of the students, which is not declared during the application process. The academic purpose of the common core program is to provide students with a strong - and shared - background on these topics. The retention rate of students from the first to the second year of the academic program at FCFM has fluctuated between $87.3 \%$ and $95.8 \%$ (median $92 \%$ ), with no significant difference between female and male students.

After completing the common core program, during their junior year, students choose one of the majors offered by 
FCFM. There are no limitations on the number of students and no special requirements for any of the majors. In addition, students can change from one major to another, although in most cases this may result in taking more years to complete the degree. During the common core program, some engineering and science departments run activities to attract students, such as breakfast with faculty and alumni, academic and scientific fairs, and workshops. However, these initiatives are not permanent and vary from year to year, because of which their influence on student choice of major seems to be limited.

The Geology Department and Geophysics Department enroll around $6 \%$ of the total undergraduate students in FCFM (Table 1). Compared to the engineering programs at FCFM, the geoscience majors are among the fields with the highest proportions of female students enrolled (Table 1). Figure 2 shows that the proportion of female students within the geology major at FCFM remained relatively steady over the period 2007-2018 (median of 33\%), with an increasing trend over the last 2 years. Moreover, the rising number of total students during the period 2009-2015 has led to an increased presence of female students in this major. In the case of geophysics, the number of students enrolled is very low and highly variable, with a relatively high proportion of female students (median of $37 \%$ ), similar to what is observed in geology.

The academic curriculum that leads to geology and geophysics majors at FCFM is unique among geoscience majors in Chile. The geoscience academic programs at other universities are specifically tailored for these majors - i.e., do not have a common core program like in FCFM - and students take geosciences courses along with mathematics and physics starting in the first year of college.

\section{Conceptual framework}

To better understand the process of female students choosing geoscience majors and experiencing them, we use a personality-environment fit framework (Porter and Umbach, 2006). This conceptual framework proposes that the interaction between personal characteristics and the college environmental context influences how successful the process of selecting and becoming a student in a specific major will be. Astin's (1993) input-environment-output (I-E-O) model suggests that a successful college experience is one in which a student's personal qualities fit the institutional environment (e.g., peer interaction, faculty culture, academic program, organizational policy, and structures). A proper fit facilitates student involvement, a sense of belonging, and ultimately the enhancement of student learning and personal development (NAE, 2004; Soria and Stebleton, 2013) (Fig. 3).

Student personality is one of the critical factors influencing choice of major and student experience, among other individual characteristics, such as race, gender, family background, and academic history (Astin, 1993). Authors in the college choice research field have conceived personality using Holland's six categories (i.e., realistic, investigative, artistic, social, conventional, and enterprising) (Porter and Umbach, 2006), Eccles' subjective task value construct (Matusovich et al., 2010), social cognitive career theory (Sexton et al., 2018), and self-determination theory (intrinsic and extrinsic sources of motivation) (Soria and Stebleton, 2013). There has been a large body of research produced using the personality-environment framework to study the gender gap in STEM majors (e.g., Martin et al., 2013; Moakler and Kim, 2014; Sexton et al., 2018; Zafar, 2013). The personalityenvironment fit seems more important for female than for male students. For instance, according to Sexton et al. (2018), personal interest and department fit are the top two reasons why women choose geology. According to these authors, personal interest means an individual's attraction to topics such as fossils, dinosaurs, geologic disasters, and a love of the outdoors. By department fit, Sexton et al. (2018) mean that students appreciate classes and interactions with faculty and peers. Furthermore, other studies report that when women are underrepresented in a STEM program, in particular if they belong to other marginalized groups (e.g., race, first-generation), peer interaction and support become key factors for a positive experience in their majors (Martin et al., 2013; Morganson et al., 2010).

On the other hand, the academic environment consists of multiple characteristics that influence the college experience (Astin, 1993). Among them, the most relevant are institutional character and type (e.g., private or public, researchor teaching-oriented), academic discipline, curricular and extracurricular opportunities, involvement with peers and faculty members, and resources such as physical facilities (e.g., laboratories, libraries) and human resources (e.g., counseling, professional academic support, teachers). Thus, we define environment as the conditions of the departments that act as pull or push factors for students choosing and experiencing a particular geoscience major.

In sum, in this study, we seek to understand how individual experiences and interests, before and during college, affect career decisions towards geosciences. The working hypothesis of this study considers FCFM to have a strong male identity, but majors like geology and geophysics have a relatively large presence of female students, and the uniqueness of the academic program is divided in two phases: the common core program and the major courses. Our first hypothesis is that current female geoscience students come to FCFM intending to major in this field, but they make the final decision influenced by positive experiences with peers or faculty members from the geoscience departments (or "pull factors") and negative experiences during their encounter with engineering fields (or "push factors") during the common core program. Our second hypothesis is that when entering the geoscience departments, the level of satisfaction of female students with the academic experience, sense of be- 

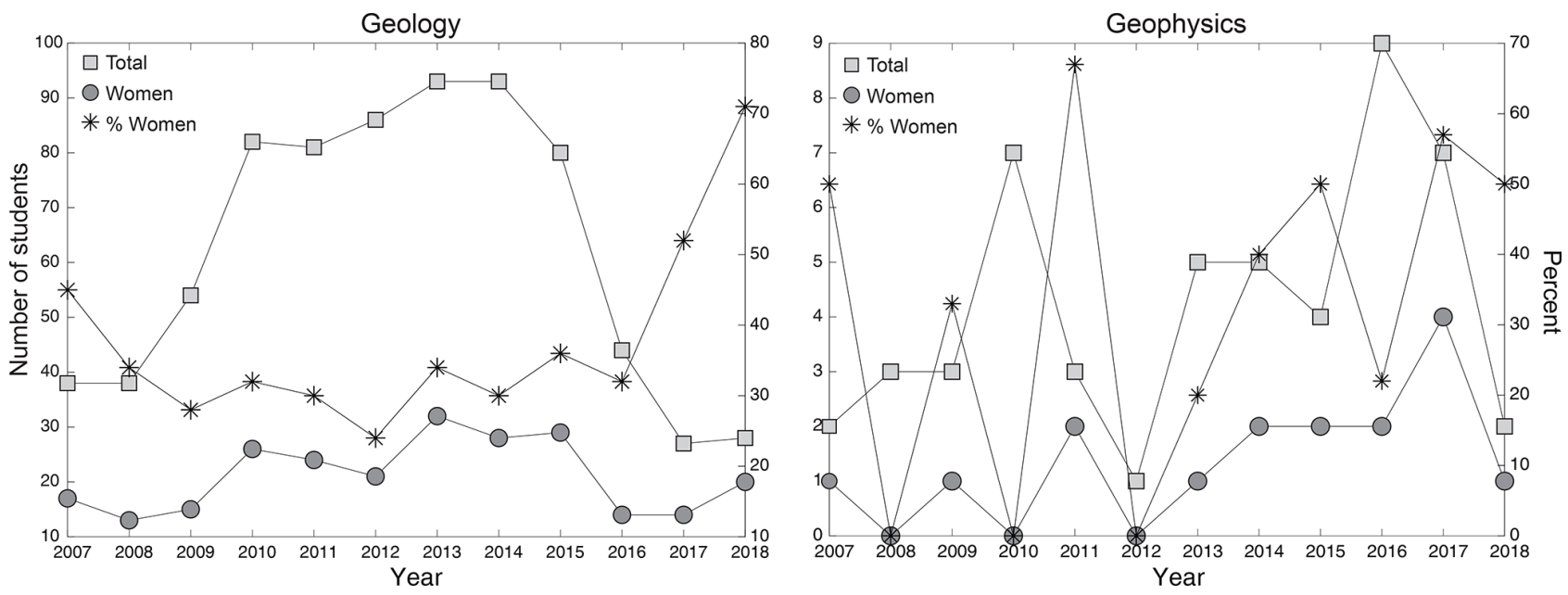

Figure 2. Number of students enrolled in geology and geophysics majors during the period 2007-2018.

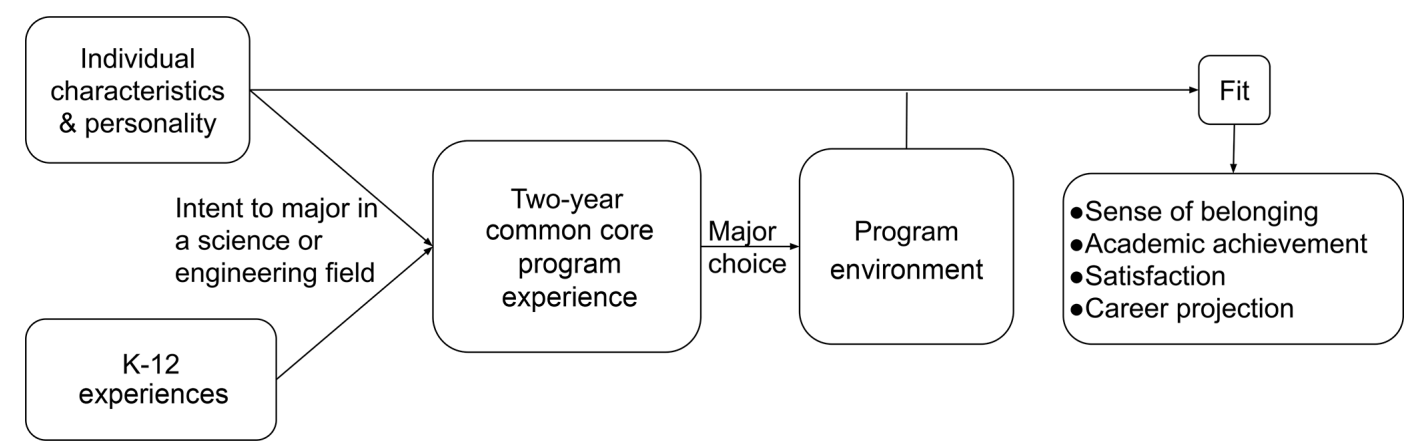

Figure 3. Personality-environment fit framework adapted for the FCFM case.

longing, and prospects in the geoscience field depend on the degree of fit between personal interests and the social and academic environment in which students are immersed (Dasgupta and Stout, 2014; Freeman et al., 2007; Soria and Stebleton, 2013). Having a relatively large proportion of female students in the geoscience majors likely presents a more welcoming environment compared to the common core program (e.g., Dasgupta and Stout, 2014). Therefore, the degree of fit between the female student and the university environment changes between the common core program (poor fit) and the geoscience major (good fit) phase of their university education. In synthesis, the research question guiding this study is the following: how do female students' experiences and interests influence their decision to study and pursue geoscience majors in a school with a male-dominated environment?

\section{Methods}

We chose to address the research question by using a case study, with semi-structured interviews as the primary source of information (George and Bennett, 2005; Creswell, 2014;
Merriam, 2009). In particular, a case study is pertinent when a contemporary phenomenon within some real-life context is being examined (Brown, 2008; Stake, 1995; Yin, 2014). The feminist movement of 2018 was a strong contemporary phenomenon that was present as we carried our investigation. We assumed that this background would lead to female participants (and us as researchers) experiencing gender issues more explicitly. We saw this movement as an opportunity to get a better grasp of what was happening with female students in their process of choosing and experiencing geoscience majors at FCFM. Thus, we used the feminist movement as a background rather than directly approaching it in the interview protocol. We present this case study with descriptive statistics on female participation in STEM disciplines, along with students' narratives to analyze the reasons female students have for pursuing geoscience majors and to explore their experiences at FCFM.

\subsection{Data collection}

To recruit student participants for this study, we distributed handouts and sent emails to current female geoscience students. After a few weeks, 12 students responded to our in- 
Table 2. Geoscience female undergraduate participants.

\begin{tabular}{|c|c|c|c|c|}
\hline Pseudonym & $\begin{array}{r}\text { Year of } \\
\text { enrollment }\end{array}$ & $\begin{array}{l}\text { Type of } \\
\text { admission }\end{array}$ & $\begin{array}{l}\text { City of } \\
\text { origin* }\end{array}$ & Major \\
\hline Agata & 2014 & Equity & Metropolitan & Geophysics \\
\hline Ambar & 2011 & Regular & Metropolitan & Geophysics \\
\hline Cristal & 2012 & Regular & Metropolitan & Geology \\
\hline Esmeralda & 2016 & Regular & Metropolitan & Geology \\
\hline Gemma & 2015 & Regular & Metropolitan & Geophysics \\
\hline Lavinia & 2015 & Regular & Small city & Geology \\
\hline Magaly & 2012 & Regular & Small city & Geology \\
\hline Perla & 2015 & Regular & Small city & Geology \\
\hline Rosa & 2012 & Regular & Metropolitan & Geology \\
\hline Ruby & 2012 & Regular & Small city & Geology \\
\hline Jade & 2012 & Regular & Small city & Geology \\
\hline Violeta & 2012 & Equity & Small city & Geology \\
\hline
\end{tabular}

Note: * metropolitan cities refer to urban areas that have a population greater than 500000 and may include a core city and nearby communities. We consider small cities those with a population of 500000 or fewer inhabitants. In our sample small cities cover a range between 70000 and 300000 inhabitants.

quiry to participate in this investigation: three students in the geophysics program and nine from the geology program. Table 2 shows the participants enrolled in FCFM before and after PEG's implementation (2012-2016). Half of them are originally from a metropolitan area, such as Santiago, the capital city of Chile.

All participants had completed the common core program at FCFM, which allowed them to select their major. Some of them may have been admitted through PEG. However, we did not ask any direct questions about PEG in order to avoid any bias in response. Indeed, university records show that none of the participants were admitted through this program. Two student participants were admitted through an equity admission program intended to attract students coming from low socioeconomic backgrounds (see Table 2).

The semi-structured interviews were conducted during the second half of 2018, so all our interviewees had at least five semesters of college experience. Most of the interviews took place towards the end of a student feminist strike. The study followed all ethical research processes required by the institution.

We recorded all interviews on digital voice recorders and took notes by hand. An interview protocol (see the complete protocol in the Appendix) was developed based on purposeful questions previously validated in similar research examining gender issues in STEM fields (Farias, 2016). The protocol begins with questions related to college choice (i.e., common core program at FCFM). Then it moves to questions about the first-year experience and the process of choosing the geoscience majors, including the evaluation of alternative programs. The protocol ends with questions related to their experience as female students in a male-dominated environment. We did not include questions explicitly related to the feminist movement since it was not the main focus of the study. However, we expected that it could be mentioned given the relevance this movement had among students at FCFM. The interviews had an average duration of $35 \mathrm{~min}$. The first two authors conducted all the interviews. These authors conducted the first two interviews together in order to check the features of the protocol and then conducted the rest of the interviews separately. All participants signed an informed consent document for their voluntary participation in this study, and confidentiality was guaranteed.

\subsection{Analysis}

Immediately after each interview, the interviewers wrote two- or three-paragraph memos, in which they shared first impressions and critical information, questions, and ideas that emerged. Then, the audiotapes were transcribed verbatim. Individual information on interviewed students was removed from each transcript before analysis, and participants were assigned a pseudonym. In order to ensure reliability, we designed an iterative process. First, one interview was analyzed by all authors, who then met to discuss the first general impressions. Second, the research team was divided into two to analyze three new interviews and created the first group of topics common to all interviews. Third, the whole team met and discussed preliminary findings and decided on the topics to focus the analysis. Finally, the rest of the interviews were analyzed by at least two authors, who met regularly to refine the coding process, discuss the emerging themes, and reinterpret subtopics when necessary. Throughout this process, we classified the responses of each participant into two main categories: (a) the principal reason they chose a geoscience major and (b) their experiences in a male-dominated school. In terms of validity, we also consulted participants' academic records to verify and complement their curricular trajectories (Leech and Onwuegbuzie, 2007); for instance, we reviewed which courses had been taken and majors declared.

All authors, except one, obtained their undergraduate degrees at FCFM, and two of them graduated from the Geology Department. The authors that performed the interviews did not have any previous relationship with the students participating in this study. We acknowledge that the interviews and the analysis of the results may be partly influenced by the personal experiences of the authors as undergraduate students at FCFM. On the other hand, our perspectives on FCFM allow us more profound insights into the studied phenomena and the ability to understand nuance. As previously explained, we compared our analyses of the interviews to verify the emerging themes and made sure that we based our results and interpretations exclusively on what was reported in the interviews.

\section{Study limitations}

This is a descriptive and preliminary study of the experience of 12 female students at a single university. Moreover, 
since the recruitment of participants was open and through email communication, sample bias was inherent. We suspect we interviewed students who were more vocal and likely with a more outspoken personality than their peers. Therefore, generalizations from the results of this investigation should be taken with caution. Despite these limitations, we took the opportunity to collect data as the feminist movement was unfolding, which gave us access to students' perceptions at a time of social activism. Nevertheless, additional research with male participants, female students in other majors, and students from geoscience programs at other universities would be needed to test how particular these experiences were to female students at FCFM. Also, evaluating the experience of female students at FCFM who did not persist in their academic programs would shed light on personal and environmental conditions that are more relevant for student retention.

\section{Results}

The results are divided into two subsections. First, we report students' experiences and interests that led them to choose geoscience as a college major. Then, we focus on the experience of women at FCFM during the common core program and geoscience specialization.

\subsection{The choice of a geoscience major}

We found that the students were inclined towards the geosciences during their precollege experience ( 9 out of 12, 9/12 forward). This early decision was reinforced during their first years in FCFM. For some, the inclination even started in elementary school (6/12). This early inclination is important at FCFM, where the first 2 years of the common core program are intended to provide an orientation to the multiple majors offered. We found that interest in and decision for the geosciences were triggered by three key themes: (i) an early interest in exploration and contact with the natural environment (9/12), (ii) the interaction with school teachers or geoscience professionals $(9 / 12)$, and (iii) a perceived personality fit with the geoscience department (12/12).

\subsubsection{Early interest: the influence of the natural landscape}

Exposure to and contact with Chile's natural landscape was a recurring theme in the interviews $(9 / 12)$. For Chileans, mountains are part of the everyday scenery, and this element of the landscape was part of the story we heard from the students interviewed. The participants recalled feeling drawn to mountains and rocks in their everyday experiences or in family trips. They enjoyed outdoor life or were curious about the landscape that surrounds them.

These experiences were consistent across different socioeconomic backgrounds. For instance, we had the case of Ma- galy, a student who came from a well-off family and who felt drawn to nature through family trips to her grandmother's country house, where she eventually came in contact with geologists exploring the area. "I had never heard about geology before, but I met them there, I understood some of what they did and that they do a lot of fieldwork, so I became very interested in it" (Magaly, geology student). Magaly's experience was similar to Perla's, who came from a low-income family. She recalled that her family did not travel during vacations, but she lived near the beach, which facilitated experiences in natural landscapes. Moreover, in her first year at the university, she volunteered for some governmental agencies to do fieldwork in natural parks in order to have the opportunity to explore the country. Perla persisted in the geosciences even though the disciplines were not well known to her family.

"[In secondary school] I did not know that there was something where I could study rocks, for instance. I used to go with my family to the beach, we would pick up rocks, and one day, when I was a child, about 10 years old, I asked to my father whether there was a way to differentiate between rocks, because I loved rocks. So, he told me, 'I have no idea'. But after that, everything gained meaning; I decided that this was for me. I wanted to study geology, and obviously I had to go to Universidad de Chile in the first place. However, I was at a high school with no history of students enrolling at this university, and I was from a region [different from the Metropolitan area], so it was more complicated" (Perla, geology student).

In addition to the natural landscape, Chile is located within a region with frequent earthquakes and many active volcanoes. Our participants reported that these features also influenced their interest in natural phenomena. For example, Cristal, a geology student, reports "I became interested in geology after the [2010] earthquake". To some extent, in Chile the geosciences are accessible to all citizens regardless of their place of birth or particular experiences during their precollege education. None of our participants referred to the mining industry as part of their early motivation. We found this surprising because Chile's economy is heavily dependent upon the mining industry (Consejo Minero, 2017), in which the majority of geoscience professionals work (Tapia et al., 2018).

\subsubsection{External encouragement from teachers and geoscience professionals}

For some students, significant experiences during high school provided an opportunity to learn about geosciences and encouraged them to pursue a career in this field (9/12). Our participants recalled that, at some point, they discovered their interest in geosciences thanks to a meaningful interaction with a science teacher or a geoscience professional. In 
the case of Lavinia, an engaging science teacher was very important to learn about geology.

"[...] the chemistry teacher was my favorite, [and] we were a group of students that used to go to the Chemistry Olympics [...] and the teacher would tell us about the majors related with chemistry, besides chemical engineering. And she told us about geology, and I liked it because I never wanted to be [working] in an office and always liked to go to the mountains" (Lavinia, geology student).

In the case of Jade, a vocational orientation activity at her high school led her to meet a geologist, which opened a new prospect for her future.

"One activity at my school was [...] to choose a profession and the school would find a professional in that field you would spend a few hours with. [...] I had chosen biochemistry, which I thought I liked, but I ended up visiting a geologist [...] She was making a map [...] that was my first encounter with geosciences. And she had studied at Universidad de Chile. I loved what she did and I asked her a lot of questions about the university, the common core program, and she said that she did not have much ability in mathematics and physics, the same I felt at the time, but she could pass the courses, she loved the university and it was the best decision she had made. Her story completely convinced me" (Jade, geology student).

\subsubsection{Personality-environment fit with the geoscience department}

Participants' early interest in geoscience led them to choose FCFM at Universidad de Chile. In all cases, enrollment at FCFM was the first choice of the interviewees among several universities with engineering and geoscience programs. Once at FCFM, they had a 2-year common core program before declaring a major, and it is frequent that students change their minds and develop other disciplinary interests. In the case of our interviewees, their preference towards geosciences did not change over this period. Moreover, it was common to hear from the participants that the academic experience during the common core program was very difficult $(7 / 12)$, with an overall lack of interest in the courses (5/12). Many discarded the idea of pursuing a major in engineering because they had no interest in the physics and mathematics courses offered and therefore it felt like a continuation of the first 2 years at FCFM (6/12). In the case of Rosa, this was a strong influence on her final decision to choose the geology major.

"[...] I imagined other majors but when I decided to persist in Beauchef ${ }^{1}$, for me the only possibil-

\footnotetext{
${ }^{1}$ Beauchef is an informal term used to refer to FCFM and comes from the name of the street where this institution is located.
}

ity was to get into geosciences. I felt that the engineering environment was not for me; I felt like an outsider here. Then for me, it was geosciences or leave and study law, psychology, or education. [...] I imagined that all engineering majors were like a continuation of the common core program" (Rosa, geology student).

In some cases, a major in geosciences seemed like an alternative to a dominant masculine environment represented by the engineering majors (5/12). Such is the case of Ambar, who had to overcome family pressure to study engineering because of its promise of a good salary and job stability. But she felt that mechanical engineering was extremely male-dominated.

"I started considering the mechanical engineering program, but I was not sure. The environment seemed very masculine, and I was tired of these masculine environments. A friend told me 'hey, you know about geophysics' because he knew I liked Earth sciences, as a hobby; I thought it was beautiful, interesting, but I had this market-minded vision. I felt I had to study engineering because it would lead to socioeconomic advancement. I also had this belief that women can do challenging things. There were all of these stigmas that were not mine. It was influenced from my high school, my dad, my mom... but I was drawn to geology, and my friend told me about geophysics. I was undecided between geology and geophysics during my second and third year. I had already discarded mechanical engineering" (Ambar, geophysics student).

In contrast to the common core program, our participants felt welcomed within the geology and geophysics departments. The most frequent factors they mentioned were a friendlier and less competitive environment than in the common core program (7/12) and a positive relationship among students and faculty members (5/12). The case of Cristal is representative of the experience we heard from participants.

"I loved general geology 2 ; I loved that class. The professor learned my name right away because I asked many questions [... I I saw everything differently while studying geology. My experience here has been much better than what I experienced in the common core program. First, because people were different. They were friendlier. Perhaps, since they enjoy nature, they are warmer than the rest [...] In geology I found a space in which I could be myself, more at peace with my personality, my interests" (Cristal, geology student).

\footnotetext{
${ }^{2}$ General geology is the first course for the geology and geophysics majors.
} 
A more equal relationship between the members of the community is also highlighted by Rosa when asked about the environment in her major.

"There was a great sense of fellowship in geology. And even though those institutionalized logics of the university are still present, the differences [among faculty, students and staff] are felt less. We used to help each other a lot. For example, during the common core program it was typical that the best students of the class would never share their notes, but in geology we all shared our notes" (Rosa, geology student).

\subsection{The experience of studying geoscience in a male-dominated school}

The first year of college was a challenge for all participants. This challenge was more difficult for those students coming from small towns outside Chilean metropolitan areas. Magaly's experience illustrates this phenomenon. She was from a small town in the countryside and although she knew about FCFM, her first-year experience was difficult and required adjustment to living in a big city. She also noticed that students coming from big and traditional single-gender high schools - known as "emblematic schools" in Chile - were better prepared academically.

"Thinking about those first 2 years, I think I never understood what FCFM was. In fact, I was from a rural area, so I was not very into social networks, WhatsApp, and those things. And this was different from students coming from the National Institute $^{3}$ or other emblematic high schools. They knew what FCFM was about. And I knew there were men, but I didn't know that I would find so many of them! Or that sometimes the environment would not be so friendly. That it would be so academically challenging. I had to study so much, I did not think it would be so so hard. So, in that regard, the challenges were outside of my expectations. On the other hand, I have learned so many things beyond engineering, such as meeting people who know certain topics that in other places are not talked about. For instance, since there is this whole topic of gender in education... I never talked about that in my high school. I come from a small town, [far from Santiago], and from a Catholic school. So, all these things were not discussed there, and here I could be more vocal about it and make up my own mind" (Magaly, geology student).

\footnotetext{
${ }^{3}$ The National Institute (Instituto Nacional in Spanish) is an allmale public high school in Santiago. It is the oldest and one of the more prestigious public schools in Chile, and many of the students at FCFM graduated from it.
}

Magaly and several other interviewees associated the common core program's competitiveness and intense academic demands with the male-dominated environment $(7 / 12)$. The students' interactions during the common core program added stress to the first years of college. For instance, a geology student, said, "there was something that bothered me a lot, during the common core program; students found it not surprising... oh, it bothered me so much... that women failed more courses than men". This statement reflects the negative stereotypes about female students that contributed to a chilly environment during the common core program. In this regard, the interviewees reported that during this period, they experienced or knew about gender discrimination occurring at FCFM (12/12). For example, Violeta remembers the environment she experienced, marked by a sense of feeling less valued by her peers.
"[...] I met a lot of men that would tell you that women are less [academically] capable; men told me I was dumb. For asking questions. In an in- troductory course to computer science, I asked for help to a [male] classmate and he said 'How dumb you are! How is it that you do not understand!'. And in general, this is quite common, like, they would look down at you for being a woman, I felt that a lot during the first year of college, but not so much years later" (Violeta, geology student).

These perceptions changed dramatically once they declared a geoscience major. All our participants reported they felt comfortable in the geology or geophysics departments and more engaged with their learning experiences than during the common core program. They felt more respected and listened to by professors and classmates in general. For instance, Ruby, a geology student, said, "in geology it was different; I started to feel more confident, you are not shy to raise your hand and ask during class." Similarly, Ambar, a geophysics student, stated, "I felt a lot more comfortable in geophysics. I did not have to be constantly validating myself or at war with my classmates [common core program]; it was like, Ok, now I can study."

The participants relate this change in environment to a larger proportion of females within the geoscience majors that are outstanding academically (9/12). Rosa reflects on this aspect:

\footnotetext{
"[in geology] there are many women, then it was different [compared to the common core program], but I have constantly felt that I am part of a minority in Beauchef, at the beginning and even sometimes these days. [...] I have always felt somehow attacked for being a woman, and within my major it has been different because I have surrounded myself of more women and in the major it is easier that women stand out, because we are more. Then, for example, in my class, the best students were
} 
all women; when someone said something like 'ah, she did well [in the exam] because she was wearing a low-cut shirt' we all knew it was a lie; in reality, the ones that knew more and had more contact with everything are women" (Rosa, geology student).

This idea is reinforced by the experience of Cristal, who felt respected by her peers in the geology major "because this university is very competitive, then the grades are very important, and the fact that we were women with good grades gave us a special status".

\subsection{The feminist movement of 2018}

The university feminist movement in the first half of 2018 was positively experienced by the students interviewed $(8 / 12)$. It represented an opportunity to have group discussions about gender issues and critically reevaluate experiences of the past. In the case of Magaly, this was a transformative experience. She highlights in her interview that she was from a small town and from a Catholic school where gender issues were not discussed. This conservative context in Chile is frequent.

"I have made more connections with other women, not only in geology. It is like a collective awakening, in which there are situations that we found natural and now we realize were not ok. Many things that I used to let go, now I see that I should have not. But it has been a group process with many women, from the Geology Assembly. Now we have a reading $\mathrm{club}^{4}$, then I feel that I have been growing along with other women" (Magaly, geology student).

A similar context is reported by Jade, who relates her cultural background to her attitudes towards the environment at FCFM during her first years of college.

"When I was in the common core program I never questioned anything; I felt privileged of being a woman in this school, but I never questioned the fact that there were more men than women or whether this was a 'machista' environment, because I come from [city in the south of Chile] and from a family, well my close family is not 'machista', but my grandmother and everybody else [extended family] are very 'machistas'. Then, there are things that I realized several years later that were not good [at FCFM]. But, back then I could not tell you if there was a moment of gender discrimination... maybe now I would notice them" (Jade, geology student).

\footnotetext{
${ }^{4}$ The reading club is a club created by female undergraduate students at FCFM to learn about feminism. They met regularly during 2018.
}

At the institutional level, Esmeralda discusses the influence of feminism in changing the interaction between students at FCFM:

"[...] how do you take responsibility about machista attitudes by freshman students. How do you make clear that science is for women and men $[\ldots]$ how do you explain to a freshman student that your female classmate is not an object, that she is a classmate only asking how to solve a class problem, and $[\ldots]$ how do you take care that teaching assistants are ready to face this world" (Esmeralda, geology student).

The role of women in the geoscience majors is mentioned by several participants that consider their female peers to be a relevant presence within the departments (6/12) and identify female professors and FCFM geoscience female alumni as role models $(4 / 12)$.

\section{Discussion}

Several studies have shown that there are multiple factors that influence the motivations for career choice, retention, and progression of women in STEM disciplines (Blackburn, 2017, and references therein). The interviews in this study reveal several years of personal and academic experiences that show that their paths to study geosciences have many similarities regardless of their social background and year of cohort. The following sections review these experiences and how they play into the journey of the students towards their major.

\subsection{Early decision: contact with nature and enriched experiences in $\mathrm{K}-12$}

The participants in this study confirm that love of the outdoors and school experiences are important factors for female interest in geoscience (Holmes and O'Connell, 2005; O'Connell and Holmes, 2011; Stokes et al., 2015). The interest in nature is manifested in students regardless of their socioeconomic background and region of origin, which in Chile has been shown to affect the level of access to public protected areas (e.g., natural reserves, national parks) for low-income families (Martinez-Harms et al., 2018). Regardless of this, the imposing landscape of Chile and the recurring geological hazards (earthquakes, volcanic eruptions, landslides, etc.) seem to spark the early interest of students in geosciences and compensate for any difficulty in visiting natural places.

The interviews in this investigation also support the idea that intentions to pursue a career in a STEM field are shaped during adolescence and that peers, the classroom, and school play a critical role in the decisions of young women (Eccles, 1994, 2009). In these cases, science teachers and school 
extracurricular activities triggered the interest of the participants in geoscience. That is, they were exposed to positive sources of influence within their local contexts (RiegleCrumb and Morton, 2017) that supported their interest.

Thus, motivated by a combination of these aspects, all but one of the participants made a decision to study geoscience during the last years of high school. This is remarkable since previous studies have shown that undergraduate experiences are the most common motivation for women to pursue geosciences (Holmes and O'Connell, 2005; O'Connell and Holmes, 2011; Sexton et al., 2018). In this regard, Stokes et al. (2015) show that undergraduate geoscience female students report more $\mathrm{K}-12$ positive experiences than male students, although the authors do not evaluate these experiences as a relevant factor in the selection of a geoscience major in college.

It is interesting that the decision made by the participants in this study did not change during the years of the common core program - even though they considered other majors and that in some cases it represented a motivation to complete the courses in the first years of college.

\subsection{The university environment}

The university experience at FCFM reinforces this early choice of major. The participants report that the common core program represented a challenge because of the academic rigor and the masculine environment. Stereotypes against women, machista jokes and comments, being ignored by professors, and academic skills under question in a maledominated school constructed an adverse university environment for female students. In such an environment, it may be difficult to create a community that would provide the means to cope with a hostile university culture (Stout et al., 2011; Dasgupta and Stout, 2014; Blackburn, 2017). A low proportion of female faculty at FCFM (17\%; Table 1) suggests scarce opportunities for finding female role models during the common core program. The lack of female role models and the over enrollment of male students have been considered key obstacles to the retention of women in STEM fields (Dasgupta and Stout, 2014). In particular, a lack of female role models or strong community support during this period likely communicated messages of not belonging or not being academically capable (poor fit with the common core environment), which affects confidence, self-efficacy, and overall interest in the courses (Herrmann et al., 2016, and references therein). These adverse experiences and feelings during the common core program resulted in push factors from any engineering major offered at FCFM.

The environment perceived by the students improved in the geoscience majors. The community of geoscience students seemed more welcoming to them, with fewer gender biases and a decreased focus on academic competition compared to the common core program, resulting in a positive academic and social experience (good fit with the geoscience

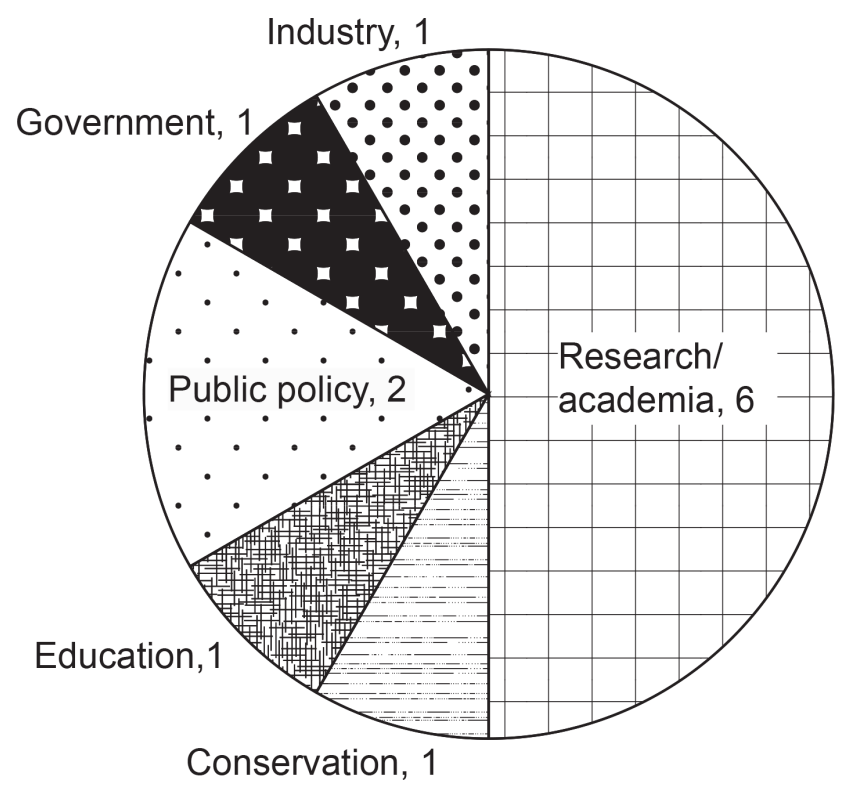

Figure 4. Preferred career paths and the number of students that reported those preferences in this study.

environment). Thus, we argue that the main academic stages of the curriculum at FCFM - the common core and the geoscience major - correspond to two different university environments that influence the personal and academic experience of the students at FCFM. The fact that female students fit the geoscience student stereotype - interested in nature and environment, liking the outdoors (e.g., Stokes et al., 2015) - probably facilitated their adaptation to the group, within which they felt respected and that they belong. However, some interviewed students felt that women were treated equal to men because women tend to be among the highest-achieving students in the major. This suggests that even in this welcoming community - still dominated by men - women need to outperform their peers to be considered equals within the group (Hill et al., 2010). Alternatively, a relatively large proportion of female students and strong female faculty members in the geoscience majors provide positive peer influences and role models to women, which in turn foster positive attitudes towards their major (Dasgupta and Asgari, 2004; Stout et al., 2011; Hernandez et al., 2018) and professional prospects in the field (Stout et al., 2011). Thus, it is not surprising that all participants report that they intend to pursue a career related to geosciences after graduation (Fig. 4). In sum, students like their geoscience departments (Sexton et al., 2018), and the related social and academic aspects represent pull factors to pursue a career in this field.

\subsection{The feminist movement and student action at FCFM}

The feminist movement of 2018 in Chile added a new perspective to the experience of the participants at FCFM. Moti- 
vated by this social movement, female students in 2018 created a female assembly at FCFM that initially gathered female students from all majors to discuss their experiences. This shows that concerns about the situation of female students at FCFM and negative experiences related to genderbased discrimination, harassment, and abuse in the university, which were the reasons for this movement (Schuster et al., 2019), were shared among the students in this school. As female students at FCFM gathered, they started to feel empowered to take action and improve their personal and collective situation. This may have also been influenced by similar movements happening simultaneously at other universities in Chile, all led by all-women assemblies, giving rise to a nationwide demand for a "nonsexist education" (Schuster et al., 2019). At FCFM, female students led a 7-week strike and took over the FCFM central administration building during July 2018 (Acuña, 2018). These actions included negotiations with university authorities to improve sexual harassment protocols at FCFM. Given the magnitude of the movement at FCFM and in the country, it is expected that most participants mentioned the feminist movement and related it to their university experience. Thus, in their voices, the movement represented a "collective journey" that female students experienced at FCFM and helped them to thematize and problematize their individual paths. The long-term effect of this feminist movement in the experience of female students in FCFM, and geosciences in particular, is something that will require analysis in the coming years. It is possible that those barriers and biases that female students confront when they want to pursue a career in geosciences will be progressively less important.

\section{Implications}

In this case study, positive experiences with nature and during high school appear to be relevant factors in the decision of female students to choose a geoscience major. From the interviews, we learned that these interests were promoted by their circumstances (family, city they live in, motivation of science teachers at school) rather than institutional efforts to promote the interest of female students in science and geoscience in particular. Geoscience courses are rare in primary and secondary school programs. Only a few of the participants reported having had exposure to some geoscience-related courses during high school, which triggered their interest in the subject. The official school curriculum in Chile (MINEDUC, 2018) contains very few geoscience topics compared to biology, physics, and chemistry, and therefore it is a subject usually overlooked in the school curriculum. Currently, one government program and a few privately funded organizations aim to motivate female K-12 students into STEM disciplines. Programs focused on geosciences will be necessary, especially considering the role of geoscience professionals in environmental challenges in the future (Gill, 2017). In this regard, a postgraduate program at FCFM that trains high school teachers in experimental classroom activities aims to encourage teachers to include some aspects of geosciences in the school curriculum.

An essential aspect of our participants' college experience was the common core program. All of them reported adverse experiences in terms of the academic curriculum and gender-based discrimination, making their persistence in the geosciences a remarkable achievement. This is relevant, considering that the participants in this study reported rare exposure to the geosciences and an absence of female role models during the common core program. The results of this study suggest that it is necessary to work on improving the institutional culture during the first 2 years of coursework and not to rely solely on female students' internal motivation and commitment to persist. In this regard, the PEG program has been successful in increasing the number of female students admitted each year at FCFM, but this does not automatically transform a historical masculine culture into a positive environment for female students. Therefore, institutional support is needed. For example, the development of mentoring programs during the common core period, in particular programs with female peer mentors, would be effective in protecting students' sense of belonging and confidence (Dennehy and Dasgupta, 2017). A recent program at FCFM designed to hire more female professors (FCFM, 2014) would also increase the possibilities for female students to find role models earlier in their university education, as long as the new faculty teach courses in the common core program. In addition, orientation programs for first-year female students and an increased number of academic experiences in which students, both female and male, can explore and get relevant information on the majors and career opportunities offered at FCFM should be made available.

Regarding early interest in the natural world, FCFM and other institutions in Chile could use this finding to promote greater student engagement from the first year. It seems that student interest in environmental issues is put on hold during the common core program instead of using it to fuel learning opportunities. For instance, more attention to the national landscape could be given across all subjects in the first year through different disciplinary lenses. As an example, a pilot program for first-year students at FCFM, in which three of the authors have participated, consists of two courses in which students work toward solutions around an environmental problem (Pinto et al., 2018). The students evaluated this program highly because it is a hands-on course with field experiences, close interaction with their peers, professors, and communities, and work on sustainable development, which gives them a purpose to pursue a career in science or engineering. In this sense, highlighting the importance of geosciences to solve current and future societal and environmental problems early in the academic curriculum might increase the number of women enrolling in these majors (e.g., Su and Rounds, 2015), especially students that 
did not develop an early interest in geosciences during their $\mathrm{K}-12$ education.

\section{Conclusions}

In this investigation we aimed to explore the motivations and experiences of female students that pursue a geoscience major at FCFM, a school with a strong masculine culture. We found that for most participants the decision to study geosciences was made while they were in high school, and they maintained their decision during the first 2 years of college in the common core program. The experience of the students at FCFM is heavily influenced by the two main stages of the academic program in this school: the common core program and the geoscience major. Academic competition and gender-based discrimination during the common core program constituted negative experiences that affected their sense of belonging and confidence. These experiences seem to represent push factors from any engineering major at FCFM, reaffirming their early decision to study geoscience.

In contrast, the students reported a welcoming environment in the geoscience majors, in which women felt comfortable, confident, and treated equally by male peers. These aspects represented pull factors to the geoscience major. A relatively large presence of women within the geoscience departments, and the fact that they were among the best students, led them to become role models for other female students. This environment led to a positive attitude towards their major, improving their academic experience and allowing them to pursue their careers within the geosciences. The 2018 feminist movement represented an opportunity for female students at FCFM to reflect on their experiences collectively, and for the students in this investigation, it provided tools to reevaluate their path in FCFM.
Given the relevance of $\mathrm{K}-12$ experiences in the career decision of the students, we consider it crucial to implement educational experiences related to geosciences, which are currently not relevant in the official school curriculum in Chile. Even though PEG has promoted an increase in the number of female students at FCFM, additional institutional programs like peer mentoring and the inclusion of sustainability topics in the common core curriculum could positively influence the social and academic experience of these students and improve their satisfaction and interest in geoscience earlier in their university education. 


\section{Appendix A: Interview protocol}

Question 1: Could you tell us why you decided to study at FCFM at Universidad de Chile? Did you have any other options in mind or other majors or universities?

Question 2: How were those first 2 years in FCFM? How did it live up to or differ from your expectations?

Question 3: Could you tell us about the process of choosing a major? What other alternatives did you have in mind? What were the factors that helped you to choose your major?

Question 4: How has your experience been in your major? How has your experience been as a woman in your major? Do you think the fact that you are female influences the relationship with your peers, professors, or staff in your major?

Question 5: What are your personal and/or professional plans for the next 5 years?

Question 6: We are conducting an investigation on the impact of gender programs in the geoscience majors at FCFM. Do you have something else related to this topic that you would like to talk about?

Thank you very much! 
Code and data availability. Transcripts of the interviews are confidential. For any additional information, please contact the lead author.

Author contributions. All authors participated in the design of this study. JPQ and SC prepared the interview protocol. TV and SC performed the interviews. All authors analyzed and discussed the interviews. TV, SC, and JPQ wrote the paper with input from LP and MR.

Competing interests. The authors declare that they have no conflict of interest.

Special issue statement. This article is part of the special issue "Diversity and equality in the geosciences (EGU2019 EOS6.1 \& US4, AGU2018 ED41B, JpGU2019 U-02)". It is a result of the AGU Fall Meeting 2018, Washington, United States, 10-14 December 2018.

Acknowledgements. We thank the Faculty of Physical Sciences and Mathematics (Universidad de Chile) for support during the development of this investigation. We acknowledge the students that participated in the interviews and consented to share their experiences as women in geosciences. Tania Villaseñor acknowledges support from project ANID PAI 77190019. Sergio Celis acknowledges support from Núcleo Milenio Experiencias de los Estudiantes de la Educación Superior en Chile. Maisa Rojas acknowledges support from project Fondecyt 1171773. Tania Villaseñor and Maisa Rojas acknowledge support from Núcleo Milenio Paleoclima. Luisa Pinto is thankful for the dedicated work of Jimena Orellana and academic assistants at FCFM in collecting statistical data for this investigation. We thank Seth Saltiel and Wil del Pilar for proofreading earlier versions of this paper. We thank editor Jill Karsten, and reviewers Emily Cooperdock and Asmeret Asefaw Berhe for their comments that helped to improve this paper.

Financial support. The publication of this paper has been supported by the Office of Equity and Gender at Universidad de O’Higgins (project URO-1856).

Review statement. This paper was edited by Jill Karsten and reviewed by Asmeret Asefaw Berhe and Emily Cooperdock.

\section{References}

Acuña, N.: La nueva cara del movimiento estudiantil: tomas y paros feministas, available at: https://radiojgm.uchile.cl/la-nueva-caradel-movimiento-estudiantil-tomas-y-paros-feministas/ (last access: 1 August 2019), 2018.

American Geosciences Institute: U.S female geosciences enrollments and degrees remain level in 2015, available at: https://www.americangeosciences.org/workforce/currents/ us-female-geoscience-enrollments-and-degrees-remain-level-2015 (last access: 29 January 2020), Geosci. Curr., 110, 2016.

Astin, A. W.: What matters in college? Four critical years revisited, Jossey-Bass, San Francisco, CA, 1993.

Beede, D. N., Julian, T. A., Langdon, D., McKittrick, G., Khan, B., and Doms, M. E.: Women in STEM: A gender gap to innovation, available at: https://www.americangeosciences.org/workforce/currents/ us-female-geoscience-enrollments-and-degrees-remain-level-2015 (last access: 29 January 2020), Geoscience Currents Data Brief 110, Economics and Statistics Administration Issue Brief No. 04-11, 2011.

Blackburn, H.: The Status of Women in STEM in Higher Education: A Review of the Literature 2007-2017, Science and Technology Libraries, 36, 235-273, 2017.

Boliver, V.: Expansion, differentiation, and the persistence of social class inequalities in British higher education, High. Educ., 61, 229-242, 2011.

Bonilla, N.: Experiencia académica de estudiantes mujeres en primer año de ingeniería, Propuestas de mejoramiento de los sistemas de apoyo a estudiantes con mirada de género, Memoria para optar al Título de Ingeniero Civil Industrial (Industrial Engineering senior thesis), Universidad de Chile, 79 p., available at: http://repositorio.uchile.cl/handle/2250/142486 (last access: 8 May 2020), 2016.

Bordón, P., Canals, C., and Mizala, A.: Gender differences in College Major Choices. The Case of Chile, Working paper, Universidad de Chile, Santiago, 2018.

Brown, L.: A review of the literature on case study research, Canadian Journal for New Scholars in Education, 1, 1-13, 2008.

Castillo, R., Grazzi, M., and Tacsir, E.: Women in science and technology. What does the literature say, available at: https://publications.iadb.org/en/ women-science-and-technology-what-does-literature-say (last access: 7 May 2020), 2014.

Clancy, P. and Goastellec, G.: Exploring access and equity in higher education: Policy and performance in a comparative perspective, High. Educ. Q., 61, 136-154, 2007.

Codling, A. and Meek, L. V.: Twelve propositions on diversity in higher education, Higher Education Management and Policy, 18, 1-24, 2006.

ComunidadMujer: Género, Educación y Trabajo. Primer estudio sobre la desigualdad de género en el ciclo de la vida. Una revisión de los últimos 25 años, available at: http://informeget. cl/wp-content/uploads/2018/07/Informe-GET-2016.pdf (last access: 24 January 2019), 2016.

ComunidadMujer: Mujer y trabajo: Brecha de género en STEM, la ausencia de mujeres en Ingeniería y Matemáticas, Serie Mujer y Trabajo, available at: http://www.comunidadmujer. cl/biblioteca-publicaciones/wp-content/uploads/2017/12/ BOLETIN-42-DIC-2017-url-enero-2018.pdf (last access: 29 January 2020), no. 42, 2017.

CONICYT: Participación Femenina en Programas de CONICYT 2007-2016, available at: http://www.conicyt.cl (last access: 14 April 2020), 2017.

Consejo Minero: Minería en números, available at: https://consejominero.cl/wp-content/uploads/2019/01/ mineria-en-numeros.pdf (last access: 7 August 2019), 2017. 
Consejo Nacional de Educación: Matrícula total de educación superior, años 2005-2019, available at: http://www.cned.cl (last access: 29 January 2020), 2019.

Creswell, J. W.: Research design: Qualitative, quantitative and mixed methods approaches (4th ed.), Sage, Thousand Oaks, CA, 2014.

Dasgupta, N. and Asgari, S.: Seeing is believing: Exposure to counterstereotypic women leaders and its effect on the malleability of automatic gender stereotyping, J. Exp. Soc. Psychol., 40, 642658,2004

Dasgupta, N. and Stout, J. G.: Girls and Women in Science, Technology, Engineering, and Mathematics: STEMing the Tide and Broadening Participation in STEM Careers, Policy Insights from the Behavioral and Brain Sciences, 1, 21-29, 2014.

Dennehy, T. C. and Dasgupta, N.: Female peer mentors early in college increase women's positive academic experiences and retention in engineering, P. Natl. Acad. Sci. USA, 114, 5964-5969, 2017.

Díaz, K., Ravest, J., and Queupil, J. P.: Brechas de género en los resultados de pruebas de selección universitaria en Chile. ¿Que sucede en los extremos superior e inferior de la distribución de puntajes? Pensamiento Educativo, Revista de Investigación Educacional Latinoamericana, 56, 1-19, 2019.

Dumas-Hines, F. A., Cochran, L. L., and Williams, E. U.: Promoting diversity: Recommendations for recruitment and retention of minorities in higher education, College Student Journal, 35, 433439, 2001

Eccles, J.: Understanding women's educational and occupational choices, Psychol. Women Quart., 18, 585-609, 1994.

Eccles, J.: Who am I and what am I going to do with my life? Personal and collective identities as motivators of action, Educ. Psychol., 44, 78-89, 2009.

Emol: Acceso de mujeres a la universidad: Los sistemas de admisión que buscan reducir la brecha de género, available at: https://vcm.emol.com/6708/noticias/ sistemas-de-admision-que-buscan-reducir-la-brecha-de-genero/, last access: 5 May 2020.

Espinoza, C.: Programa PEG: Protagonistas de un cambio revolucionario, available at: http://ingenieria.uchile.cl/noticias/153561/ programa-peg-protagonistas-de-un-cambio-revolucionario (last access: 6 May 2020), 2019.

European Commission: She figures 2012. Gender in Research and Innovation: Statistics and Indicators, Publications Office of the European Union, Luxemburgo, 2013.

Farias, J.: Mujeres Ingeniería UC y Más Mujeres para la Ingeniería y las Ciencias de la U. de Chile: Una mirada al impulso del acceso, experiencia y permanencia de las mujeres en las carreras ingenieriles y científicas en Chile, Thesis, available at: http://repositorio.uchile.cl/handle/2250/143480 (last access: 5 May 2020), 2016.

FCFM: FCFM pondrá en marcha Programa de Equidad de Género en la Academia, available at: http://ingenieria.uchile.cl/noticias/103151/fcfm-pondra-enmarcha-programa-de-equidad-de-genero-en-la-academia (last access: 25 April 2020), 2014.

Freeman, T. M., Anderman, L. H., and Jensen, J. M.: Sense of belonging in college freshmen at the classroom and campus levels, J. Exp. Educ., 75, 203-220, 2007.
Geological Society of America: Removing Barriers to $\mathrm{Ca}$ reer Progression for Women in the Geosciences, available at: https://www.geosociety.org/documents/gsa/positions/pos26_ RemovingBarriersToWomen.pdf (last access: 25 April 2020), 1 6, 2018.

George, A. and Bennett, A.: Case Studies and Theory Development in the Social Sciences, 4th edn., MIT Press, Cambridge, MA, 2005.

Gill, J. C.: Geology and the Sustainable Development Goals, Episodes, 40, 70-76, 2017.

Gurin, P., Dey, E., Hurtado, S., and Gurin, G.: Diversity and Higher Education: Theory and impact on educational outcomes, Harvard Educational Review, 72, 330-367, 2002.

Hernandez, P. R., Bloodhart, B., Adams, A. S., Barnes, R. T., Burt, M., Clinton, S. M., Du, W., Godfrey, E., Henderson, H., Pollack, I. B., and Fische, E. V.: Role modeling is a viable retention strategy for undergraduate women in the geosciences, Geosphere, 14, $1-9,2018$.

Herrmann, S. D., Adelman, R. M., Bodford, J. E., Graudejus, O., Okun, M. A., and Kwan, V. S.: The effects of a female role model on academic performance and persistence of women in STEM courses, Basic Appl. Soc. Psych., 38, 258-268, 2016.

Hill, C., Corbett, C., and St Rose, A.: Why so few? Women in Science, Technology, Engineering, and Mathematics, American Association of University Women (AAUW), Washington, D.C., 2010.

Holmes, M. A. and O'Connell, S.: Where are the Women Geoscience Professors?, NSF-AWG Workshop, available at: http://eas2.unl.edu/ mholmes/pub.htm (last access: 30 September 2020), 2005.

Leech, N. L., and Onwuegbuzie, A. J.: An array of qualitative data analysis tools: a call for data analysis triangulation, School Psychology Quarterly, 22, 557-584, 2007.

Marginson, S., Tytler, R., Freeman, B., and Roberts, K.: STEM: country comparisons: international comparisons of science, technology, engineering and mathematics (STEM) education, Final report, Australian Council of Learned Academies, Melbourne, 2013.

Martin, J. P., Simmons, D. R., and Yu, S. L.: The role of social capital in the experiences of hispanic women engineering majors, J. Eng. Educ., 102, 227-243, 2013.

Martinez-Harms, M. J., Bryan, B. A., Wood, S. A., Fisher, D. M., Law, E., Rhodes, J. R., Dobbs, C., Biggs, D., and Wilson, K. A.: Inequality in access to cultural ecosystem services from protected areas in the Chilean biodiversity hotspot, Sci. Total Environ., 636, 1128-1138, 2018.

Matusovich, H. M., Streveler, R. A., and Miller, R. L.: Why do students choose engineering? A qualitative, longitudinal investigation of students' motivational values, J. Eng. Educ., 97, 289-304, 2010.

Mendes Braga, M.: Inclusão e equidade: desafios para a educação superior na América Latina e no Caribe na próxima década, in: Tendencias de la educación superior en América Latina y el Caribe, edited by: Gazzola, A. L. and Didrikson, A., IESALCUNESCO, Caracas, 2008.

Merriam, S.: Qualitative research: A guide to design and implementation, 2nd edn., Jossey-Bass, San Francisco, CA, 2009. 
MINEDUC: Programas de Estudio, available at: https:// curriculumnacional.mineduc.cl/614/w3-propertyvalue-118605. html (last access: 7 May 2020), 2018.

Moakler, M. W. and Kim, M. M.: College major choice in STEM: Revisiting confidence and demographic factors, Career Dev. Q., 62, 128-142, 2014.

Morganson, V. J., Jones, M. P., and Major, D. A.: Understanding Women's Underrepresentation in Science, Technology, Engineering, and Mathematics: The Role of Social Coping, Career Dev. Q., 59, 169-179, 2010.

Naidoo, R.: Higher education as a global commodity: the perils and promises for developing countries, The Observatory on Borderless Higher Education, London, 2007.

National Academy of Engineering (NAE): The Engineering of 2020: Visions of Engineering in the New Century, National Academy Press, Washington, D.C., 2004.

O'Connell, S. and Holmes, A.: Obstacles to the recruitment of minorities into the geosciences: A call to action, GSA Today, 21, 52-54, 2011.

OECD: The pursuit of Gender Equality: An Uphill Battle, OECD Publishing, Paris, 2017.

OECD/CAF/ECLAC: Latin American Economic Outlook 2016: Towards A New Partnership with China, OECD Publishing, Paris, https://doi.org/10.1787/9789264246218-en, 2015.

PEG: Programa de Ingreso Prioritario de Equidad de Género. Ingeniería, Universidad de Chile, available at: http://ingenieria.uchile.cl/admision/admision-especial-pregrado/ 94355/cupos-equidad-de-genero, last access: 25 April 2020.

Pfeffer, F. T.: Persistent inequality in educational attainment and its institutional context, Eur. Sociol. Rev., 24, 543-565, 2008.

Pinto, L., Rojas, M., MacLean, C., Peric, D., Bravo, E., Célèry, F., Díaz, F., Valenzuela, R., Vicencio, V., and Celis, S.: Programa iGea: Apoyo a la formación de ingenieros y geocientíficos para el desarrollo sustentable. XV Congreso Geológico Chileno, available at: https://congresogeologicochileno.cl/libro-de-actas/ (last access: 6 May 2020), Libro de Actas, 47, 2018.

Porter, S. R. and Umbach, P. D.: College major choice: An analysis of person-environment fit, Res. High. Educ., 47, 429-449, 2006.

Queupil, J. P. and Durán, F.: El Principio de Inclusión: Similitudes y Diferencias en la Educación Escolar y Superior en Chile, Revista Latinoamericana de Educación Inclusiva, 12, 111-128, 2018.

Riegle-Crumb, C. and Morton, K.: Gendered Expectations: Examining How Peers Shape Female Students' Intent to Pursue STEM Fields, Front. Psychol., 8, 2017.

Rosen, J.: Data illuminate a mountain of molehills facing women scientists, Eos, 98, https://doi.org/10.1029/2017EO066733, 2017.

Salinas, P. and Romaní, G.: Proyección Laboral de las Estudiantes Mujeres en Carreras Mineras en la Educación Superior Chilena, Formación Universitaria, 10, 31-48, 2017.

Salinas, P., Romaní, G., and Silva, J.: Gender equality or diversity in the mining industry for 2035? Crossroads for Chilean higher education, Journal of Education and Work, 31, 628-644, 2019.

Schuster, S., Santos, A., Miranda, L., Roque, B., Arce-Riffo, J., and Medel, E.: Una mirada al movimiento feminista en Chile del año 2018: hitos, agenda y desafíos, Iberoamericana, 19, 223-245, 2019.
Sepúlveda, M. J. and Manquepillán, M.: Brechas de género en el Sistema Único de Admisión a la educación superior, Documento de trabajo no. 2, available at: http://biblioteca.digital.gob. cl/handle/123456789/390 (last access: 6 May 2020), 2017.

Servicio de Información de Educación Superior, SIES: Informe Matrícula 2019 en educación superior en Chile, available at: http://www.mifuturo.cl, Ministerio de educación, 2019.

Sexton, J. M., Pugh, K. J., Bergstrom, C. M., and Riggs, E. M.: Reasons undergraduate students majored in geology across six universities: The importance of gender and department, Journal of Geoscience Education, 66, 319-336, 2018.

Seymour, E.: Tracking the processes of change in US undergraduate education in science, mathematics, engineering, and technology, Sci. Educ., 86, 79-105, 2002.

Shavit, Y. (Ed.): Stratification in higher education: A comparative study, Stanford University Press, Palo Alto, CA, 2007.

Soria, K. M. and Stebleton, M.: Major Decisions: Motivations for Selecting a Major, Satisfaction, and Belonging, NACADA Journal, 33, 29-43, 2013.

Stake, R.: The Art of Case Study Research, Sage, Thousand Oaks, CA, 1995.

Stokes, P. J., Levine, R., and Flessa, K. W.: Choosing the Geoscience Major: Important Factors, Race/Ethnicity, and Gender, Journal of Geoscience Education, 63, 250-263, 2015.

Stout, J. G., Dasgupta, N., Hunsinger, M., and McManus, M. A.: STEMing the tide: Using ingroup experts to inoculate women's self-concept in science, technology, engineering, and mathematics (STEM), J. Pers. Soc. Psychol., 100, 255-270, 2011.

$\mathrm{Su}, \mathrm{R}$. and Rounds, J.: All STEM fields are not created equal: People and things interests explain gender disparities across STEM fields, Front. Psychol., 6, 1-20, 2015.

Tapia, J., Tolorza, V., Durán, P., Poblete, N., and Schneider, B.: Assessment of geologic programs in higher educational institutions of Chile, Int. J. Educ. Dev., 59, 70-85, 2018.

UNESCO: Latin America and the Caribbean, Education for All 2015 Regional Review, available at: http://unesdoc.unesco.org/ images/0023/002327/232701e.pdf (last access: 2 May 2020), 2014.

UNESCO: Cracking the code: Girl's and women's education in science, technology, engineering, and mathematics (STEM), available at: https://unesdoc.unesco.org/ark:/48223/ pf0000253479 (last access: 30 September 2020), 2017.

UNESCO: UNESCO eAtlas of Research and Experimental Development, available at: https://www.tellmaps.com/uis/rd/\#! /tellmap/-1341198154/3, last access: 16 January 2019.

Villalobos, C., Treviño, E., Wyman, I., and Scheele, J.: Social justice debate and college access in Latin America: merit or need? The role of educational institutions and states in broadening access to higher education in the region, Education Policy Analysis Archives, 25, 73, 2017.

World Bank: Higher Education in Developing Countries: Peril and Promise, The World Bank, Washington, D.C., 2000.

Yin, R.: Case Study Research Design and Methods, 5th edn., Sage, Thousand Oaks, CA, 2014.

Zafar, B.: College major choice and the gender gap, J. Hum. Resour., 48, 545-595, 2013. 